\title{
Understanding the impact of teacher's formative feedback on students' self-reflection behavior and learning motivation
}

\author{
Xiaoquan $\operatorname{Pan}^{1}$ and Zhengdong Gan ${ }^{2}$ \\ Received date: 23 / 04 / 2019 \\ Accepted date: $30 / 06 / 2019$
}

\begin{abstract}
This article presents the results of questionnaire surveys on the impact of teacher's formative feedback on students' self-reflection behavior, self-reflection strategy and learning motivation conducted with 152 English major students from a teacher-education-oriented university in China. The study found the significant impact of teacher's formative feedback on students' self-reflection practices and learning motivation. The findings also showed that freshmen have stronger plasticity and are more susceptible to teacher's feedback. Therefore, it is suggested that teachers should do a good job in the mode and method of positive evaluation feedback from the freshman year, and stick to it, so as to lay a good foundation for students' learning motivation development, learning strategy improvement and self-reflection behavior.
\end{abstract}

Keywords: Teacher's formative feedback; students' self-reflection behavior; learning motivation; self-regulated learning

\section{Introduction}

Teacher feedback can play a key role in students' learning process, performance and development. Researches have shown that teacher feedback, when provided properly and targeted at the appropriate facet, can effectively affect students' learning behavior and help promote their desired performance (Hattie \& Timperley, 2007). A report from Shute (2008) also demonstrated that teacher's feedback can be a powerful motivator particularly when it is connected to students' goal-driven efforts. The positive effect of teacher's feedback was emphasized by Shute (2008) using the term 'formative feedback' which was defined as 'information communicated to the learner that is intended to modify his or her thinking or behavior for the purpose of improving learning"' (154). Formative feedback accelerates students' learning by encouraging them to be engaged in a continuous loop of self-assessment based on particular criteria (Leahy et al., 2005). In the process of providing feedback, teachers need to adopt appropriate strategies so as to make feedback more effective. The research from Fluckiger et al (2010) provided a formative feedback model by giving feedback in time for revisions to occur, providing scaffolding for learners, informing instruction, and most importantly, involving students as partners in assessment, showing that these strategies brought about the benefits of improved instruction, enhanced students' learning, and contributed to a productive classroom climate. Some researchers such as Butler (1987), and Stiggins $(2001 ; 2008)$ contended that effective formative feedback must be specific, taskbased and goal-oriented, allowing learners to set clear expectations of themselves, modify selfreflection strategies and conduct self-reflection behaviors that influence their own successes. To

${ }^{1}$ Corresponding author, Xingzhi College, Zhejiang Normal University, Jinhua, Zhejiang Province, China Institute of Foreign Linguistics and Applied Linguistics, Zhejiang Normal University, Jinhua, Zhejiang Province, China pxq@zjnu.cn

${ }^{2}$ Faculty of Education, University of Macau, Macao, China 
Pan, X., Gan, Z, (2019). Understanding the impact of teacher's formative feedback on students' self-reflection behavior and learning motivation. International Journal of Social Sciences and Education Research, 5(3), 233241.

ensure that teachers' formative feedback can result in students' greater learning motivation, Cauley \& McMillan (2010) discussed five key practices: 1) provide clear learning targets; 2) offer feedback about progress toward meeting learning; 3 ) attribute student success and mastery to moderate effort; 4) encourage student self-assessment; and 5) help students set attainable goals for improvement. Therefore, it can be seen that the significance of teacher's formative feedback and the key feedback strategies are highlighted by current literatures. However, there is an element that might be neglected, that is, the role of learner. It implies that teacher's feedback needs to be formulated, delivered and constructed in a way that can invite learners' active engagement. Researches indicated that only providing feedback from teachers does not really involve students, and thus students need to actively conduct self-reflection behaviors related to their own learning (Boud \& Falchikov, 2007). Sadler (2010) emphasized the need to observe and analyze students' understanding of the feedback information and their active response to it in learning practices. Boud (2000) claimed that " unless students are able to use the feedback to produce improved work, through, for example, redoing the same assignment, neither they, nor those giving the feedback, will know that it has been effective" (158). Therefore, there is a necessity to investigate the impact of teacher's feedback on students' learning behavior change and how students of different levels respond to it in diverse ways.

This study, which involves 152 undergraduate students majoring in English, aims to investigate what formative feedback and feedback strategy from teachers they experience, and how these factors relate to their self-reflection behavior and strategy, thus ultimately influencing their learning motivation. Examining the relationships between teachers' formative feedback and students' learning behavior and motivation helps to provide insight into the optimal feedback practices that contribute to most desirable outcomes of student motivation and learning. Since the 152 undergraduate students are from three different grades, this study further intends to explore the potential differences on related variables and results, which enables us to recognize the necessity of adopting differentiated feedback strategies and practices to accelerate students' learning at different levels.

\section{Literature review}

Formative feedback, which is regarded as a pedagogical instrument in helping students' learning experience, can effectively promote learning if it is appropriately applied. For Black \& Wiliam (2009), formative feedback is "a formative interaction in which an interactive situation influences cognition, i.e., it is an interaction between external stimulus and feedback, and internal production by the individual learner which involves looking at the three aspects, the external, the internal and their interactions" (11). Therefore, the objective of formative feedback is to promote the deep involvement of students in meta-cognitive strategies by giving students "the power to steer their own learning so that they can become a more committed, responsible and effective learner" (Black \& Jones 2006, p. 8). Formative feedback, when used by students as a learning mechanism, can reduce uncertainty on how well they themselves performed in learning, which leads to students' higher learning motivation and self-regulated behavior (Song \& Keller, 2001). Furthermore, according to Shute (2008), formative feedback can reduce students' cognitive load, potentially promote learning, and provide useful information for correcting misconceptions. Noticeably, in nearly every learning situation, motivation and engagement are important areas to be interrelated with formative feedback because there is a clear link between motivation, engagement, time-on- 
Pan, X., Gan, Z, (2019). Understanding the impact of teacher's formative feedback on students' self-reflection behavior and learning motivation. International Journal of Social Sciences and Education Research, 5(3), 233241.

task and learning outcomes (Keller, 2009). The research outcomes from some researchers (such as Ecclestone, 2010; Slavich, \& Zimbardo, 2012) indicated that formative feedback enables students to set goals, evaluate their performance and change their learning approaches, while actively engaging themselves in learning; improving knowledge and skills; and becoming independent learners.

Despite its importance, however, some researches also suggest that students at times failed to actively engage in the feedback process due to the lack of motivation and self-reflection behavior. To strengthen the role and effects of formative feedback on students' learning motivation and engagement, Hatziapostolou \& Paraskakis (2010) presented an online feedback system to enhance the quality of feedback and motivate students to engage with feedback. In order to support students' self-regulation behavior, Dannefer \& Prayson (2013) explored the relationship between problem-based feedback and students' self-reported behavioral improvements in their assessment portfolios, finding that formative feedback helped the improvement of students' learning performance and students utilized external formative feedback to document their portfolio self-assessment in a system designed to support self-regulation behaviors. Çakir et al (2016) explored students' preferences for formative feedback and its relationship with their self-regulated learning skills, indicating that students with higher self-regulated learning skills preferred formative feedback than the students who have lower self-regulated learning skills. This study enables educators to better understand how to overcome the difficulty of providing proper formative feedback in relation to students' self-regulated learning skill that is considered to be an essential quality in a lifelong learning era.

\section{Research design}

A total of 152 undergraduate students majoring in English in a teacher-education-oriented university in Eastern China were recruited to participate in this study. Among the 152 participants, 52 students are freshmen with 39 female and 13 male, 46 students are sophomores with 43 female and 3 male, and 54 students are juniors with 45 female and 9 male. The age of the participants ranged from 18 to 22 years with $\mathrm{M}$ age $=19.58$ years, $\mathrm{SD}$ age $=1.058$ years.

The participants in this study completed a questionnaire concerning teacher's formative feedback, teacher's feedback strategy, participants' self-reflection behavior, participants' self-reflection strategy and learning motivation in English teaching and learning practices. 8 items related to different aspects of teacher's formative feedback and 11 items concerning teacher's feedback strategies were constructed in reference to current conceptualization of teacher feedback originated from Hattie \& Timperley (2007), Nicol \& Macfarlane-Dick (2006), and Harris, Brown, \& Harnett (2014). Participants were asked to indicate their agreement with these different aspects of teacher feedback practices on a 6-point Likert scale, ranging from 1 (not at all used) to 6 (used very often). The participants' self-reflection behavior (9 items) and strategies (11 items) were elicited using the same 6-point Likert scale with total 20 items (1 being "strongly disagree" and 6 being "strongly agree") informed by the research of Peltier, Hay \& Drago (2005), and Kember et al (2000) which indicated that the self-reflection process and strategies consisted of three elements: awareness (the process in which a person becomes conscious of a previous experience), critical analysis (identifying existing knowledge and finding possible alternatives for a specific situation), and change (the transformation of practices and beliefs). Additionally, participants' learning motivation was also elicited using the same 6-point Likert scale with 15 items (1 being 
Pan, X., Gan, Z, (2019). Understanding the impact of teacher's formative feedback on students' self-reflection behavior and learning motivation. International Journal of Social Sciences and Education Research, 5(3), 233241.

"strongly disagree" and 6 being "strongly agree") adapted from existing foreign language learning motivation scales (e.g. Guilloteaux \& Dörnyei, 2008; Kormos \& Csizer, 2014). The questionnaire data were analysed through use of SPSS 22.0. Pearson Product-Moment Correlation (r) analysis and multivariate analysis of variance (MANOVA) were carried out to examine the relationships between formative feedback practices, feedback strategy, students' self-reflection behavior, students' self-reflection strategy and learning motivation as well as the multiple comparisons of different grade students' learning motivation, self-reflection behavior and self-reflection strategy.

\section{Findings and implications}

The descriptive statistics of the questionnaire was shown in Table 1. The Cronbach's $\alpha$ coefficients for the five scales range from 0.802 to 0.941 , suggesting good reliability. In contrast, participants' response to teacher's formative feedback was the least positive and showed the most difference among all the other categories, indicating that under China's language teaching contexts teacher's formative feedback is inadequate and thus should be enhanced. Students' selfreflection behavior in response to teacher's formative feedback was rated slightly above a neutral 4 suggesting in China students' learning was generally greatly influenced by teacher's instruction and their learning behavior tended to be other-directed. What is noteworthy is that teacher's feedback strategy was rated as being the highest agreed $(\mathrm{M}=5.13)$, showing that students highly appreciated teacher's feedback strategies and expected those strategies to be beneficial to their learning. Possibly influenced by teacher's feedback strategies, the variable of students' self-reflection strategy was rated as being comparatively high $(\mathrm{M}=4.78)$, suggesting a possible significant correlation between the two and the correlation would be analyzed later. With regard to learning motivation, the participants elicited a very good outcome $(M=5.03)$, suggesting a generally high level of motivation in their willingness to learn and effort investment in learning.

Table 1. Descriptive statistics and reliability coefficients (Cronbach's alpha) of teacher's formative feedback, students' self-reflection behavior and learning motivation.

\begin{tabular}{llll}
\hline Scales & Mean & SD & Reliability \\
\hline Teacher's formative feedback & 3.87 & 0.875 & 0.810 \\
Students' self-reflection behavior & 4.10 & 0.801 & 0.802 \\
Teacher's feedback strategy & 5.13 & 0.678 & 0.916 \\
Students' self-reflection strategy & 4.78 & 0.751 & 0.867 \\
Students' learning motivation & 5.03 & 0.721 & 0.941 \\
\hline
\end{tabular}

Table 2 Correlation matrix

\begin{tabular}{llllll}
\hline Scales & TF & SB & TS & SS & SM \\
\hline TF & $(1)$ & & & & \\
SB & $.772^{* *}$ & & & & \\
TS & $.378^{* *}$ & $.414^{* *}$ & $(1)$ & & \\
SS & $.459^{* *}$ & $.470^{* *}$ & $.629^{* *}$ & & \\
SM & $.473^{* *}$ & $.430^{* *}$ & $.513^{* *}$ & $.529^{* *}$ & $(1)$ \\
\hline ** Corrations'
\end{tabular}

**. Correlation is significant at $\mathrm{p}<.01$ level (2-tailed). $T F$ teacher's evaluation feedback, $S B$ students' self-reflection behavior, $T S$ teacher's feedback strategy, $S S$ students' self-reflection strategy, $S M$ students' learning motivation 
Pan, X., Gan, Z, (2019). Understanding the impact of teacher's formative feedback on students' self-reflection behavior and learning motivation. International Journal of Social Sciences and Education Research, 5(3), 233241.

As can be seen in Table 2, the correlation matrix among the above five scales was measured and the correlation is significant. Teacher's formative feedback was significantly positively correlated with students' self-reflection behavior. This suggests that the more the teacher gave formative feedback, the more likely students experienced positive self-reflection learning processes. Teacher' feedback strategy was also positively correlated with students' self-reflection feedback strategy, suggesting that in China's cultural contexts students' learning methods were greatly influenced by teacher's instruction. Additionally, Table 2 also demonstrated that there is a significant correlation between students' learning motivation and other 4 constructs.

To further investigate the multiple regression between students' learning motivation and other 4 constructs, the ANOVA analysis was conducted. The dependent variable is students' learning motivation, while predictors include four constructs: teacher's formative feedback, teacher's feedback strategy, students' self-reflection behavior, and students' self-reflection strategy. The summary of model showed the result with $\mathrm{r}=0.662, \mathrm{DW}=1.680, \mathrm{df}=4$, mean square $=7.619, \mathrm{~F}=23.248$ and sig. $=0.000$, suggesting a good reliability and there is at least one of the 4 constructs significantly influenced students' learning motivation. The multiple regression analyses were further conducted and the Coefficients' data is presented in Table 3.

Table 3 Coefficients ${ }^{\mathrm{a}}$ model reporting unstandardized (B) and standardized beta's $(\beta)$ and standard errors (SE) for predictors of students' learning motivation

\begin{tabular}{llllllll}
\hline Predictors & $\mathrm{B}$ & $\mathrm{SE}$ & $\beta$ & $\mathrm{t}$ & Sig. & Tolerance & VIF \\
\hline TF & .209 & .085 & .254 & 2.464 & .015 & .393 & 2.546 \\
SB & .011 & .094 & .013 & .122 & .903 & .383 & 2.614 \\
TS & .276 & .090 & .259 & 3.072 & .003 & .586 & 1.706 \\
SS & .234 & .084 & .244 & 2.775 & .006 & .540 & 1.850 \\
& & & & & & & \\
\hline
\end{tabular}

a. Dependent Variable: Students' learning motivation. $T F$ teacher's formative feedback, $S B$ students' self-reflection behavior, $T S$ teacher's feedback strategy, $S S$ students' self-reflection strategy, $S M$ students' learning motivation

This shows that students' learning motivation was significantly positively influenced by teacher's formative feedback, teacher's feedback strategy and students' self-reflection strategy. In this study, teacher formative feedback, on the one hand, refers to feedback practices that gave the opinion or comment on a student's homework or other forms of work (Harris, Brown, \& Harnett, 2014), and on the other hand requires students to be involved as partners in the assessment of learning and to use assessment results to change their own learning tactics (Popham, 2008). This kind of formative feedback not only spiritually motivated students' learning but also actually instructed students with knowledge and helped students improve their learning approaches. Meanwhile, teacher's feedback strategies such as 'introducing strategies to improve English proficiency', 'pointing out which aspects of a student's learning need to be improved, and how to improve', and 'giving written comments on a student's work or assignments', were able to help students better improve their learning and also positively influenced students' selfreflection strategy. It can thus be seen that the meaning of teacher's feedback and students' selfreflection feedback strategy documented in this study was consistent with the conceptualization of Hattie and Timperley's feedback both at the process level and at the self-regulation level. This helps us to comprehend that the previous studies on feedback models were able to be utilized effectively to conduct current feedback practices and understand the potential meanings of positive feedback. Additionally, this study shows that in the present research context, teacher's 
Pan, X., Gan, Z, (2019). Understanding the impact of teacher's formative feedback on students' self-reflection behavior and learning motivation. International Journal of Social Sciences and Education Research, 5(3), 233241.

feedback strategy appeared to be most powerful in predicting students' positive motivational processes (Sig. $=0.003$ ), indicating the role and significance of teacher's formative feedback on students' work.

Bedsides, to further perceive the impact of teacher's formative feedback on students at different student levels, this study conducted the comparative analysis of students' learning motivation, self-reflection behavior and self-reflection feedback strategy from three grades investigated.

Firstly, with regard to students' learning motivation, this study found that the first-year students' learning motivation $(\mathrm{M}=5.447, \mathrm{SD}=0.536)$ was significantly higher than those of the second-year students $(\mathrm{M}=4.761, \mathrm{SD}=0.744)$ and the third-year students $(\mathrm{M}=4.860, \mathrm{SD}=0.688)$. The multiple comparison result was shown at Table 4 . As can be seen, there was a significant difference on students' learning motivation between the first-grade students and second-grade students or third-grade students. However, there was no significant difference between the second-grade students and third-grade students. This indicated that since the first-grade students just entered the university, they had comparatively stronger plasticity and learning motivation, therefore more likely to be influenced by teacher's formative feedback.

Table 4 Multiple comparison of different grade students' learning motivation and self-reflection behavior

\begin{tabular}{|c|c|c|c|c|c|c|c|}
\hline \multirow[t]{2}{*}{ Grade } & & \multicolumn{3}{|c|}{ Students' learning motivation } & \multicolumn{3}{|c|}{ Students' self-reflection behavior } \\
\hline & & $\begin{array}{l}\text { Mean Differ- } \\
\text { ence }\end{array}$ & Std. Error & Sig. & Mean Difference & Std. Error & Sig. \\
\hline \multirow[t]{2}{*}{$1^{\text {st }}$ grade } & $2^{\text {nd }}$ grade & $.68657^{*}$ & .13338 & .000 & $.80732 *$ & .14131 & .000 \\
\hline & $3^{\text {rd }}$ grade & $.58694^{*}$ & .12803 & .000 & $.87433^{*}$ & .13564 & .000 \\
\hline \multirow[t]{2}{*}{$2^{\text {nd }}$ grade } & $1^{\text {st }}$ grade & $-.68657^{*}$ & .13338 & .000 & $-.80732 *$ & .14131 & .000 \\
\hline & $3^{\text {rd }}$ grade & -.09962 & .13222 & .452 & .06701 & .14007 & .633 \\
\hline \multirow[t]{2}{*}{$3^{\text {rd }}$ grade } & $1^{\text {st }}$ grade & $-.58694^{*}$ & .12803 & .000 & $-.87433 *$ & .13564 & .000 \\
\hline & $2^{\text {nd }}$ grade & .09962 & .13222 & .452 & -.06701 & .14007 & .633 \\
\hline
\end{tabular}

*. The mean difference is significant at the 0.05 level.

Secondly, as for students' self-reflection behavior, this study found that the first-year students' self-reflection behavior $(\mathrm{M}=4.662, \mathrm{SD}=0.713$ ) was significantly higher than those of the secondyear students $(\mathrm{M}=3.855, \mathrm{SD}=0.676)$ and the third-year students $(\mathrm{M}=3.788, \mathrm{SD}=0.701)$. The multiple comparison result was shown at Table 4 . As can be seen, there was a significant difference on students' self-reflection behavior between first-grade students and second-grade students or third-grade students. However, there was no significant difference between second-grade students and third-grade students. This also indicated the first-grade students' stronger plasticity and controllability, so they were more likely to be influenced by teacher's formative feedback. 
Pan, X., Gan, Z, (2019). Understanding the impact of teacher's formative feedback on students' self-reflection behavior and learning motivation. International Journal of Social Sciences and Education Research, 5(3), 233241.

Thirdly, this study also found that the first-year students' self-reflection strategy ( $M=5.141$, $\mathrm{SD}=0.711)$ was significantly higher than those of the second-year students $(\mathrm{M}=4.445, \mathrm{SD}=0.676)$ and the third-year students $(\mathrm{M}=4.740, \mathrm{SD}=0.711)$, suggesting that the first-year students' selfreflection strategy was more easily influenced by teacher's feedback strategy while at the same time, compared with the second-year students, the third-year students were more capable of selfreflection strategies. The multiple comparison result was shown at Table 5. As can be seen, there was a significant difference on students' self-reflection behavior among all the three grades.

Table 5 Multiple comparison of different grade students' self-reflection strategy

\begin{tabular}{lllll}
\hline Grade & & Mean Difference & Std. Error & Sig. \\
\hline \multirow{2}{*}{$1^{\text {st }}$ grade } & $2^{\text {nd }}$ grade & $.69537^{*}$ & .14184 & .000 \\
& $3^{\text {rd }}$ grade & $.40028^{*}$ & .13616 & .004 \\
\multirow{2}{*}{$2^{\text {nd }}$ grade } & $1^{\text {st }}$ grade & $-.69537^{*}$ & .14184 & .000 \\
& $3^{\text {rd }}$ grade & $-.29509^{*}$ & .14061 & .038 \\
\multirow{2}{*}{$3^{\text {rd }}$ grade } & $1^{\text {st }}$ grade & $-.40028^{*}$ & .13616 & .004 \\
& $2^{\text {nd }}$ grade & $.29509^{*}$ & .14061 & .038
\end{tabular}

*. The mean difference is significant at the 0.05 level.

In summary, the findings suggest that teacher's formative feedback effectively enhanced students' learning motivation and autonomy. The participants' positive perception of and response to self-reflection behavior and learning strategy concurred with related research findings that emphasized teachers' contribution to students' learning behavior changes and learning outcomes, often referred to as "teacher effects" (Darling-Hammond, 2013; Hanushek \& Rivkin, 2010; Ruzek et al., 2015). This finding reveals that facilitating teacher's formative feedback is a key to supporting and motivating students' learning and thus can be utilized as an effective educational intervention (Brookhart, 2008; Hattie \& Yates, 2014). In addition, the findings showed that freshmen have stronger plasticity and are more susceptible to teacher's evaluation feedback. Therefore, it is suggested that teachers should do a good job in the mode and method of positive evaluation feedback from the freshman year, and stick to it, so as to lay a good foundation for students' learning motivation development, learning strategy improvement and self-reflection behavior. Certainly, the students in this study experienced predominantly teacher evaluation feedback and teacher feedback strategy. It is likely that this predominance of teacher-based feedback may result in students' over-dependency on teacher feedback while neglecting student-centered self-reflection feedback practices, which goes counter to the spirit of the international rise of student-centred pedagogy and Assessment for Learning policies. Therefore, an implication of the results is that while emphasizing and strengthening teacher's evaluation feedback, we should highlight that students' self-reflection feedback and peer feedback practices may have the potential to support students to become motivated and self-regulated learners, especially if such self-reflection strategy and practices are contextualized as important and observable part of the pre-service teachers' development or as necessary skills for lifelong learners.

\section{Disclosure statement}

No potential conflict of interest was reported by the authors. 
Pan, X., Gan, Z, (2019). Understanding the impact of teacher's formative feedback on students' self-reflection behavior and learning motivation. International Journal of Social Sciences and Education Research, 5(3), 233241.

\section{Funding}

This work was supported by the classroom teaching reform project of Zhejiang province's higher education funded by Department of Education of Zhejiang Province [grant number $\mathrm{kg} 20160564]$.

\section{References}

Black, P., \& Jones, J. (2006). Formative assessment and the learning and teaching of MFL: Sharing the language learning road map with learners. Language Learning Journal, 34, 4-9.

Black, P., \& Wiliam, D. (2009). Developing the theory of formative assessment. Educational Assessment, Evaluation and Accountability, 21(1), 5-31.

Boud, D. (2000). Sustainable assessment: Rethinking assessment for the learning society. Studies in Continuing Education, 22(2), 151-167.

Boud, D. J., \& Falchikov, N. (2007). Introduction assessment for the longer term. In D. J. Boud \& N. Falchikov (Eds.), Rethinking assessment in higher education (pp. 3-13). London: Routledge.

Brookhart, S. M. (2008). How to give effective feedback to your students. Alexandria, VA: Association of Supervision and Curriculum Development.

Butler, R. (1987). Task-involving and ego-involving properties of evaluation: Effects of different feedback conditions on motivational perceptions, interest, and performance. Journal of Educational Psychology, 79(4), 474-482.

Çakir, R., Korkmaz, Ö., Bacanak, A., \& Arslan, Ö. (2016). An exploration of the relationship between students' preferences for formative feedback and self-regulated learning skills. Malaysian Online Journal of Educational Sciences, 4 (4), 14-30.

Cauley, K. M., \& McMillan, J. H. (2010). Formative assessment techniques to support student motivation and achievement. The Clearing House: A Journal of Educational Strategies, Issues and Ideas, 83(1), 16.

Dannefer, E. F., \& Prayson, R. A. (2013). Supporting students in self-regulation: Use of formative feedback and portfolios in a problem-based learning setting. Medical Teacher, 35(8), 655-660.

Darling-Hammond, L. (2013). Getting teacher evaluation right: What really matters for effectiveness and improvement. New York: Teachers College Press.

Ecclestone, K. (2010). Transforming formative assessment in lifelong learning. Berkshire, UK: McGrawHill Education.

Fluckiger, J., Vigil, Y. T., Pasco, R., \& Danielson, K. (2010). Formative feedback: Involving students as partners in assessment to enhance learning. College Learning, 58(4), 136-140.

Guilloteaux, M. J., \& Dörnyei, Z. (2008). Motivating language learners: A classroom-oriented investigation of the effects of motivational strategies on student motivation. TESOL Quarterly, 42(1), 55-77.

Hanushek, E. A., \& Rivkin, S. G. (2010). Generalizations about using value-added measures of teacher quality. American Economic Review, 100(2), 267-271.

Harris, L. R., Brown, G. T. L., \& Harnett, J. A. (2014). Understanding classroom feedback practices: A study of New Zealand student experiences, perceptions, and emotional responses. Educational Assessment, Evaluation and Accountability, 26(2), 107-133. 
Pan, X., Gan, Z, (2019). Understanding the impact of teacher's formative feedback on students' self-reflection behavior and learning motivation. International Journal of Social Sciences and Education Research, 5(3), 233241.

Hattie, J., \& Timperley, H. (2007). The power of feedback. Review of Educational Research, 77 (1), 81112.

Hattie, J., \& Yates, G. (2014). Using feedback to promote learning. In V. A. Benassi, C. E. Overson \& C. M. Hakala (Eds.), Applying science of learning in education: Infusing psychology science into the curriculum (pp.45-58). Washington, DC: Division 2, American Psychological Association.

Hatziapostolou, T., \& Paraskakis, I. (2010). Enhancing the impact of formative feedback on student learning through an online feedback system. Electronic Journal of E-Learning, 8 (2), 111-122.

Keller, J. M. (2009). Motivational design for learning and performance: The ARCS model approach. New York, NY: Springer.

Kember, D., Leung, D. Y., Jones, A., Loke, A. Y., McKay, J., Sinclair, K., Tse, H., Webb, C., Wong, F. K. Y., Wong, M., \& Yeung, E. (2000). Development of a questionnaire to measure the level of reflective thinking. Assessment \& Evaluation in Higher Education, 25(4), 381-395.

Kormos, J., \& Csizer, K. (2014). The interaction of motivation, self-regulatory strategies, and autonomous learning behavior in different learner groups. TESOL Quarterly, 48(2), 275-299.

Leahy, S., Lyon, C., Thompson, M., \& Wiliam, D. (2005). Classroom assessment: Minute by minute, day by day. Educational Leadership, 63(3), 19-24.

Nicol, D. J., \& Macfarlane-Dick, D. (2006). Formative assessment and self-regulated learning: A model and seven principles of good feedback practice. Studies in Higher Education, 31 (2), 199-218.

Peltier, J. W., Hay, A., \& Drago, W. (2005). The reflective learning continuum: Reflecting on reflection. Journal of Marketing Education, 27(3), 250-263.

Popham, J. (2008). Transformative assessment. Alexandria, VA: Association for Supervision and Curriculum Instruction.

Ruzek, E. A., Domina, T., Conley, A. M., Duncan, G. J., \& Karabenick, S. A. (2015). Using value-added models to measure teacher effects on students' motivation and achievement. The Journal of Early Adolescence, 35(5-6), 852-882.

Sadler, D. R. (2010). Beyond feedback: Developing student capability in complex appraisal. Assessment and Evaluation in Higher Education, 35(5), 535-550.

Shute, V. J. (2008). Focus on formative feedback. Review of Educational Research, 78 (1), 153-189.

Slavich, G. M., \& Zimbardo, P. G. (2012). Transformational teaching: Theoretical underpinnings, basic principles, and core methods. Educational Psychology Review, 24, 569-608.

Song, S. H., \& Keller, J.M. (2001). Effectiveness of motivationally adaptive computer-assisted instruction on the dynamic aspects of motivation. Educational Technology Research and Development, 49(2), 522.

Stiggins, R. J. (2001). Student-involved classroom assessment. Upper Saddle River, NJ: Merrill Prentice Hall.

Stiggins, R. J. (2008). Student-involved assessment for learning. Upper Saddle River, NJ: Merrill Prentice Hall. 